\title{
Risk Factors and Types of Presenile Cataract in Patients Attending a Tertiary Care Hospital in Kerala- A Retrospective Study
}

\author{
Dhanya V S', Manju Abraham², Deepa MG $^{3}$ \\ ${ }^{1}$ Associate Professor, Department of Ophthalmology, Government Medical College Ernakulam, India \\ ${ }^{2}$ Professor, Department of Ophthalmology, Government Medical College Ernakulam, India \\ ${ }^{3}$ Assistant Professor, Department of Ophthalmology, Government Medical College Ernakulam, India
}

Corresponding Author: Dhanya V S

\begin{abstract}
Background: Cataract is a major cause of blindness worldwide with a greater prevalence in developing countries like India. Presenile cataract refers to an onset of this disease below 50 years of age.

Objectives: To study the factors associated with development of presenile cataract among the total cataract patients who attended out-patient clinic of Ophthalmology department from January 2016 to July 2017 and to find out the proportion of different types of presenile cataract.

Method: The study includes patients who had undergone cataract surgery in the Department of Ophthalmology Government Medical College, Ernakulam from January 2016 and June 2017. Data was retrospectively entered and analysed.

Results: There were 100 (49 males and 51 females) patients between the age 30 and 50 years. Around 70 study participants had comorbidities. The average axial length was $22.5532 \mathrm{~mm}$, the average haemoglobin content was $13.01 \mathrm{~g} / \mathrm{dL}$, average total count was 8590.85 , average BL urea was $22.755 \mathrm{mg} / \mathrm{dL}$, average serum creatinine concentration was $0.9611 \mathrm{mg} / \mathrm{dL}$ and average GRBS concentration was $131.43 \mathrm{mg} / \mathrm{dL}$. Drug history of 69 patients was observed in the current study.

Conclusion: The most common type of cataract seen was posterior subcapsular cataract followed by mature cataract. Diabetes mellitus was the predominant risk factor in posterior subcapsular cataract.
\end{abstract}

Keywords: Presenile cataract; Risk factors; Posterior subcapsular cataract

\section{INTRODUCTION}

Cataract is the clouding of the lens in the eye leading to decrease in vision. Cataract is primarily a disease of older age groups ${ }^{[1]}$. Age-related senile cataract is the commonest eye disorder causing visual impairment and preventable blindness worldwide, accounting for nearly $48 \%$ of all blindness ${ }^{[2]}$. The prevalence of cataract is higher in females than males in the developed and developing countries. In developing countries, cataract occurs at an earlier age ${ }^{[3]}$. Population-based studies have reported high prevalence rates of cataract in India compared with western populations ${ }^{[4-}$ 6]. Environmental, nutritional, and genetic factors may be important explanatory factors of these high rates, but till date, there is limited information on these in the Indian setting ${ }^{[7]}$.

Presenile cataract is defined as the opacification of lens and/or its capsule before the age of 50 years when all other known causes of cataract have been ruled out ${ }^{[8-10]}$. This will definitely add on to the already existing burden of age-related cataract in India and worldwide. Some of the landmark studies have clearly established several factors contributing to both age related as well as presenile cataract formation.

The Beaver Dam Study in Wisconsin concluded significant association of cigarette smoking with cataract ${ }^{[11]}$. A population-based cohort study in Australia 
identified the association of cigarette smoking and dietary deficiencies in vitamins and proteins with cataract. Brown observed the relationship between vitamin D deficiency and posterior subcapsular cataract ${ }^{[12]}$. Lee observed that risk factors like diabetes mellitus, high myopia, occupational exposure to metal work, atopic dermatitis, and smoking were responsible for presenile cataract ${ }^{[13]}$. In another study, risk factors like steroid use, alcohol use, cigarette smoking, and exposure to sunlight were identified ${ }^{[14]}$. The Blue Mountains Eye Study was a similar study conducted in urban community of Australia which was conducted to identify the risk factors for age-related cataract formation such as dietary factors, smoking, alcohol consumption, medications, and refractive errors ${ }^{[15]}$.

Hence, we conducted our study in an attempt to identify the potentially modifiable risk factors of presenile cataract. The primary objective of this study was to study the factors associated with development of presenile cataract among the total cataract patients who attended outpatient clinic of Ophthalmology department from January 2016 to July 2017. The secondary objective this study was to find out the proportion of different types of presenile cataract.

\section{METHOD}

This retrospective study was conducted in the Department of Ophthalmology, Government Medical College, Ernakulam, Kerala, India over a period of 3 months from August 2017 to October 2017. A sample of 100 patients who had undergone cataract surgery in the Department of Ophthalmology Government Medical College, Ernakulam from January 2016 and June 2017 (one and half years) between the age 30 and 50 years were included in this study. Additionally, all the selected study subjects provided their consent to participate in this study. Exclusion criteria for participants involved any patients suffering from congenital cataract, previous intraocular surgery, previous history of ocular trauma, uncontrolled glaucoma, history of intraocular inflammation and patients who declined their consent to participate in this study. The records of the patients who underwent cataract surgery were reviewed in detail with emphasis on demographic profile, occupation, co-morbidities, drug history, history of atopy, environmental factors like hours of outdoor activity, exposure to heavy metals and behavioural factors.

Data was collected using the study proforma. Visual acuity testing by using Snellen's chart, anterior segment evaluation done by TOPCON slit lamp, intra ocular pressure measurement was done by Goldman applanation tonometer. Dilatation of pupil was done using topical $1 \%$ tropicamide eye drops. Slit lamp examination was performed again to confirm the presence of cataract and to analyse the type of cataract. Posterior segment evaluation was done by using direct and indirect ophthalmoscope. 'A' scan was done in all the patients to determine the axial length. Preoperative blood investigations included complete blood count, renal function and electrolytes, urine routine and serology.

Sample size calculation: According to a study by Manoj Vasudevan et al in Tamil Nadu, $38.9 \%$ of the patients having presenile cataract were doing outdoor activities for more than 4 hours. Based on this data and using the formula $3.84 \mathrm{X} \mathrm{p} \mathrm{X}$ $\mathrm{q} / \mathrm{d} 2$, the minimum sample size for the present study was fixed to be 100. $3.84=$ square of ' $z$ ' value of alpha errors $5 \%=$ 1.96. $\mathrm{p}=$ proportion from previous study. $\mathrm{q}=100-\mathrm{p} . \mathrm{d}=$ absolute precision taken as 9 . All the patients with presenile cataracts attending the OPD and who underwent surgery during the study period will be included in the sample. According to the current statistics in the Government Medical College, around 100 patients with presenile 
cataract will be covered during the study period.

Statistical analysis: Coded data was entered in MS Excel spread sheet. Data analysis was done using SPSS. Qualitative data- the association between the exposure variables (outdoor activity, drug history, atopy etc.) and outcome variables (presenile cataract) were tested using Chi-square test. $p$ value $<0.05$ was considered as significant. The types of presenile cataract were expressed as frequency and percentage. Odds ratio 95\% CI was calculated.

Informed written consent was taken after informing the participants about the possible benefits, risks and implications of the study. Strict confidentiality of their personal details and information related to the study was maintained at all level.

\section{RESULTS}

This retrospective study has been carried out at the Department of Ophthalmology, Government Medical College, Ernakulam, Kerala, India over a period of 3 months from August 2017 to October 2017. In this study, initially a total of 132 patients were found eligible. But, 32 were excluded based on the exclusion criteria and those who didn't want to participate. So, a total of 100 patients who had undergone cataract surgery in the department of Ophthalmology Government Medical College Ernakulam from January
2016 and June 2017 (One and half years) between the age 30 and 50 years were studied. The following data makes an attempt to summarize the details of observations noted during the study.

Of the 100 patients studied, there were 49 males and 51 females. The mean age of the study population was 46.7 years. In both groups, majority of the patients were in the age group of 40-50 years [Figure 1].

The percentages of occupation and hot environment working status distribution in the patients are shown in Figure 2 and Figure 3, respectively. Figure 4 demonstrated alcohol and tobacco consumption distribution of the study population. The percentages of risk factors associated with presenile cataracts in the patients are shown in Figure 5. The type of cataract observed in the current study was extrapolated in Figure 6. The percentages of risk factors associated with different morphological types of cataract are shown in Figure 7.

In our study 70 study participants had co-morbidities. Upon calculation in the study participants, the average axial length was $22.5532 \mathrm{~mm}$, the average haemoglobin content was $13.01 \mathrm{~g} / \mathrm{dL}$, average total count was 8590.85 , average BL urea was 22.755 $\mathrm{mg} / \mathrm{dL}$, average serum creatinine concentration was $0.9611 \mathrm{mg} / \mathrm{dL}$ and average GRBS concentration was 131.43 $\mathrm{mg} / \mathrm{dL}$. Drug history of 69 patients was observed in the current study Figure 8.

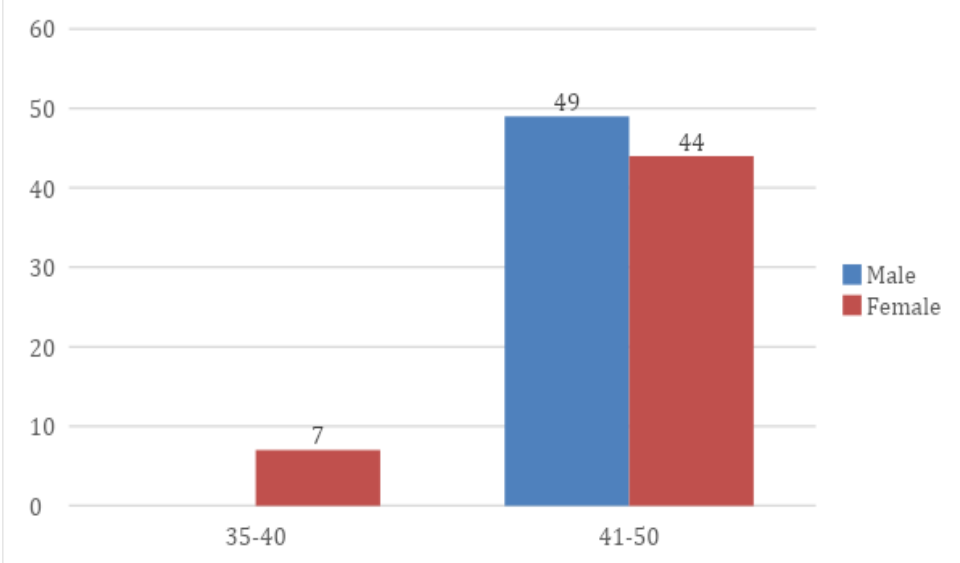

Figure 1: Age and gender distribution of the study population 
Dhanya V S et.al. Risk factors and types of presenile cataract in patients attending a Tertiary Care Hospital in Kerala- a retrospective study.

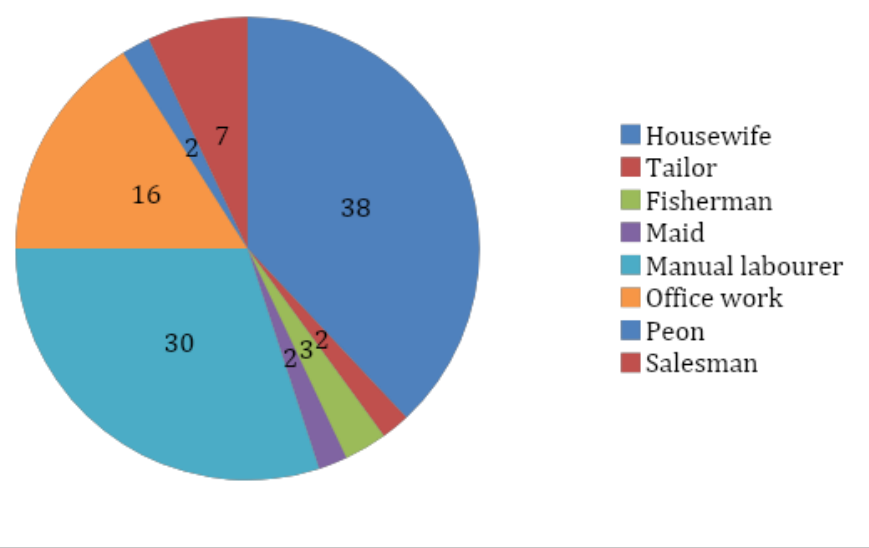

Figure 2: Occupational distribution of the study population

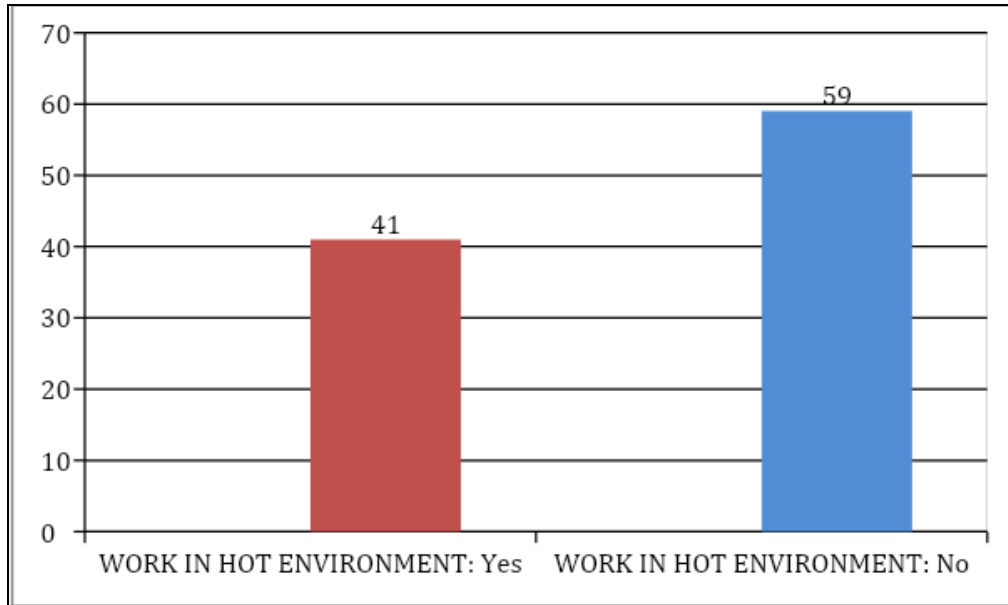

Figure 3: Hot environment working status distribution of the study population

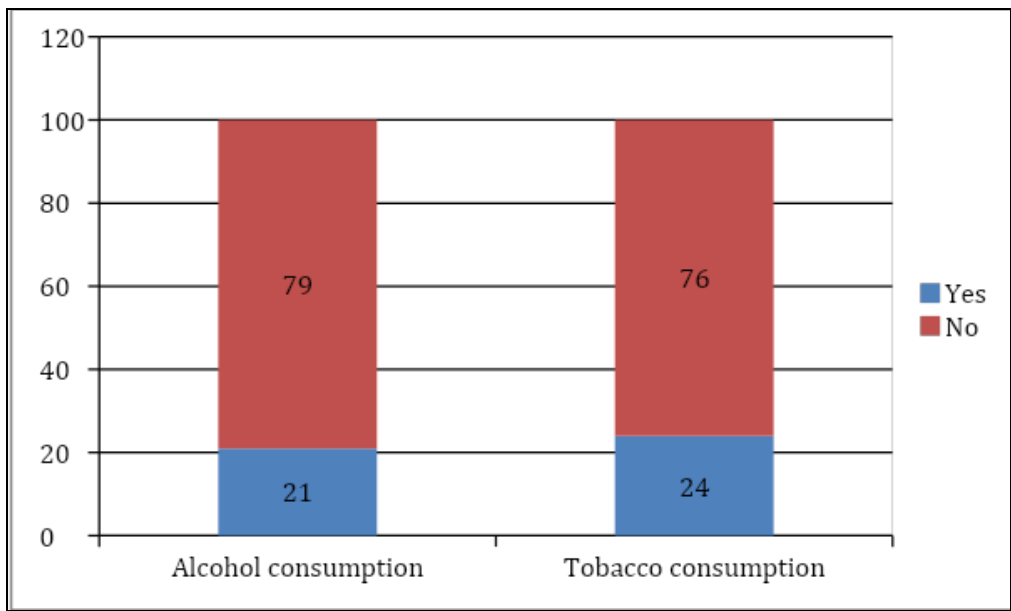

Figure 4: Alcohol and Tobacco consumption distribution of the study population

According to the above figure 6 , the most common type of cataract seen was posterior subcapsular cataract $(47 \%)$, followed by mature cataract $(18 \%)$, Immature cataract $(17 \%)$, Nuclear sclerosis
(13\%), and Others (5\%). Others include RE IMSC, LE MSC, LE IMSC, IMSC BE, RE dense posterior subcapsulary cataract and RE pseudophakia, LE immature cortical cataract. 
Dhanya V S et.al. Risk factors and types of presenile cataract in patients attending a Tertiary Care Hospital in Kerala- a retrospective study.

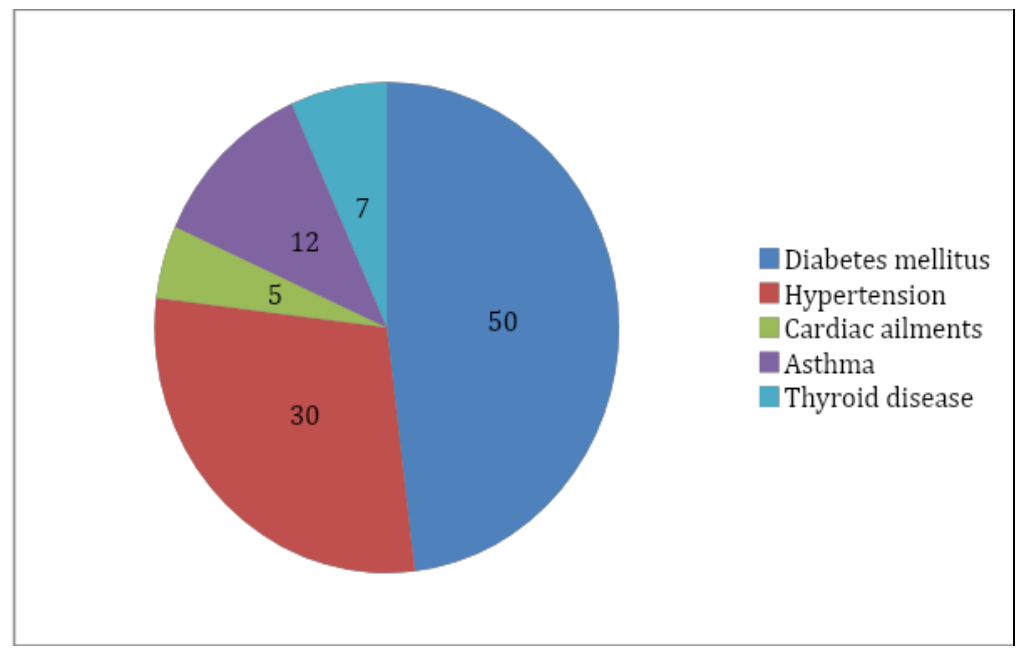

Figure 5: Risk factors associated with presenile cataracts

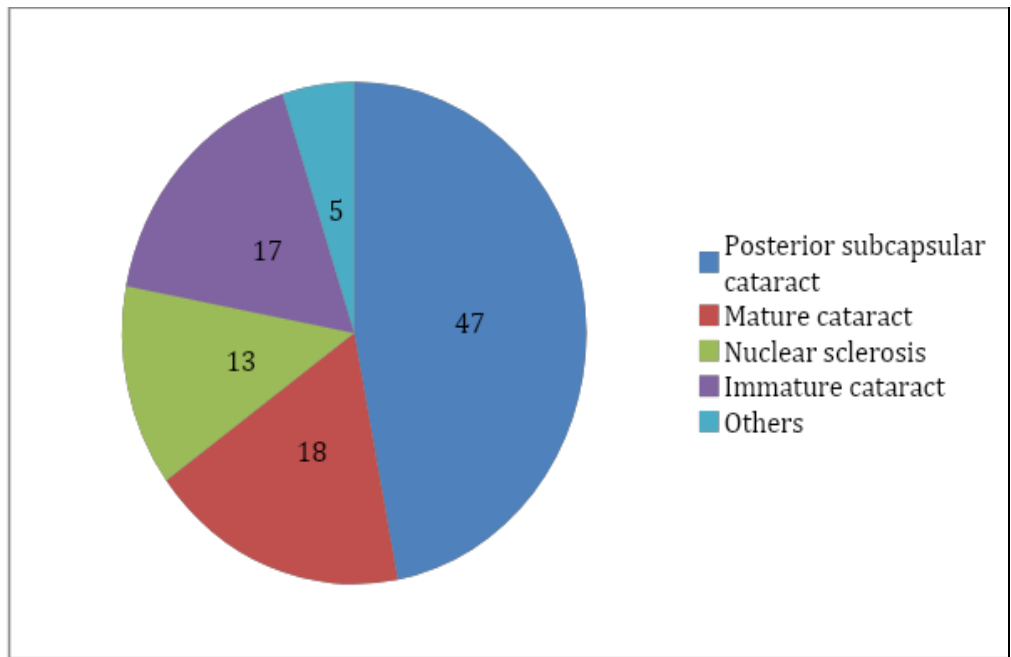

Figure 6: Morphological types of cataract

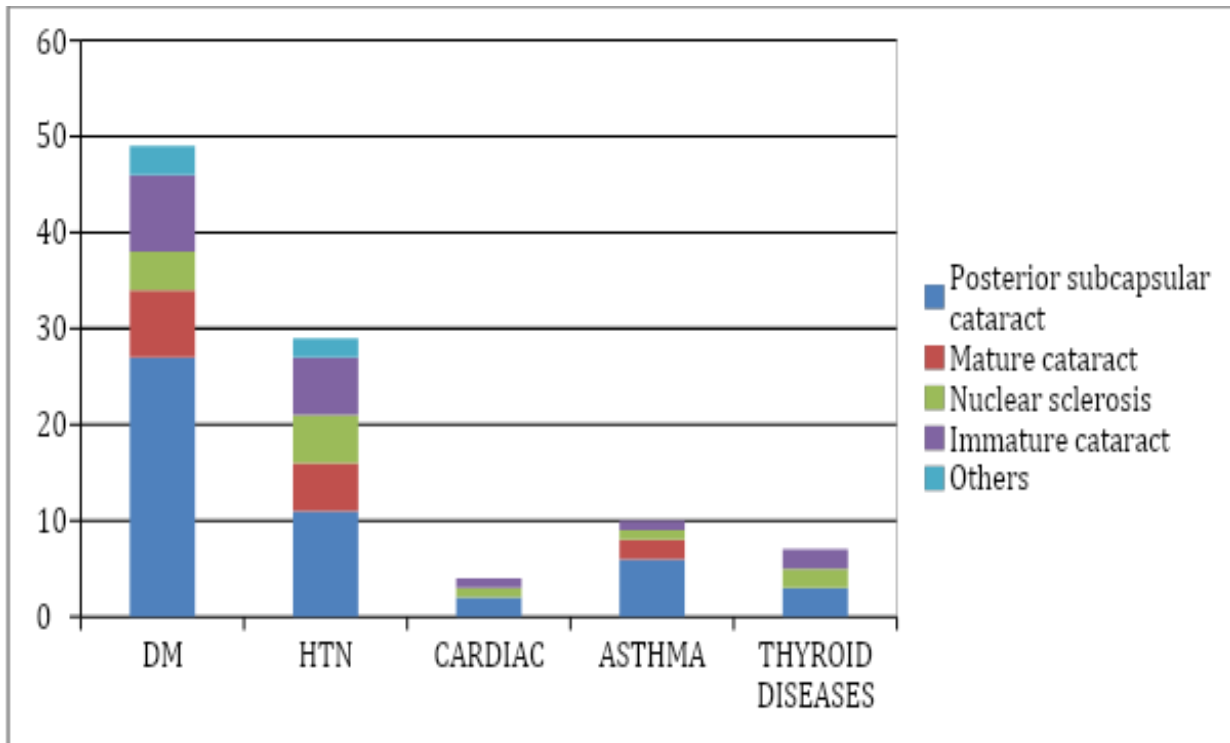

Figure 7: Risk factors associated with different morphological types of cataract 


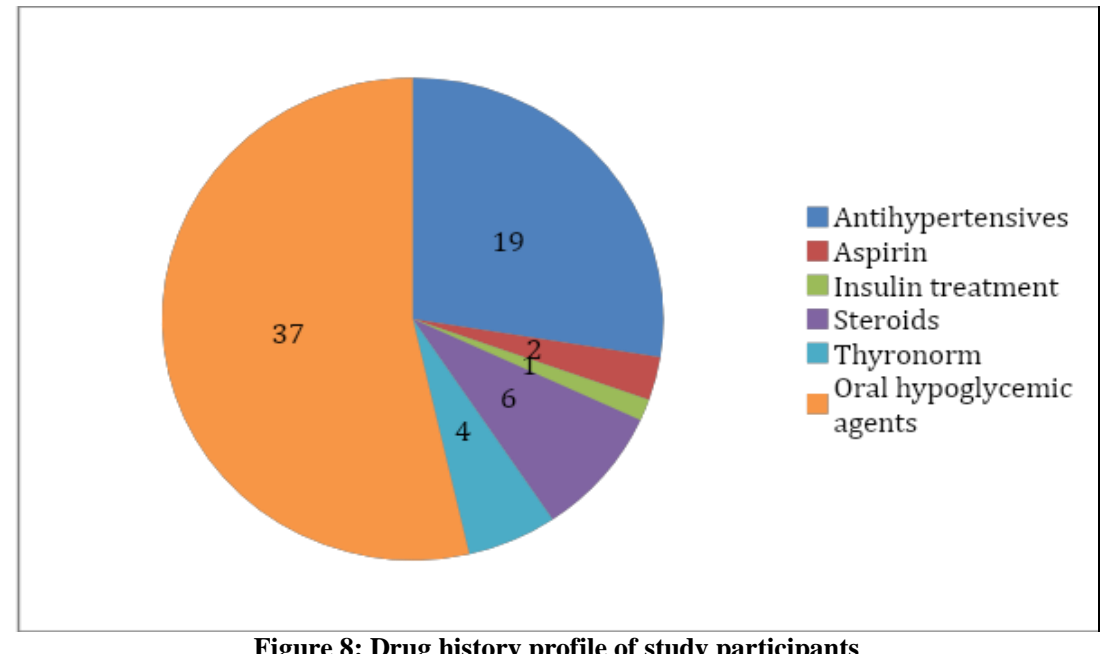

Figure 8: Drug history profile of study participants

\section{DISCUSSION}

Though cataract accounts for $62.6 \%$ of blindness in India, the risk factors of presenile cataract in India have been evaluated in very few studies ${ }^{[16]}$. Many risk factors that could have triggered the early development of cataracts were reported in our research ${ }^{[17]}$. Different risk factors were implicated with some patients. In a study conducted in western India to investigate the risk factors for the early onset of cataracts in India by Vashist et al., atopy was found to be the most common risk factor associated with cataract formation, being associated with $25.6 \%$ of cases ${ }^{[18]}$. A higher correlation of cataracts with DM was found in our research.

The most common morphological form of cataract is the posterior subcapsular cataract [19]. In all risk factor categories, it was also the most prevalent form of cataract. In a study conducted in Western India and another study conducted in the Northern part of India, similar results were published ${ }^{[20]}$. The fact that PSC produces more and faster vision deterioration than other forms of cataract may be another potential explanation for the elevated prevalence of PSC, because patients who are symptomatic earlier will report cataract surgery earlier. Therefore, the share of PSC in the population could potentially be overestimated $^{\text {[21]. }}$.

The merit of this research is that Kerala's comparatively large sample size represents extensive access to the patients' medical records. The drawback of this work is that this was small sample size, like most of the previous studies. More insights about the aetiology and modifiable risk factors would have been generated by a large sample size.

\section{CONCLUSION}

Our study concludes that diabetes mellitus, hypertension and asthma are the most common risk factors associated with presenile cataract. Further, diabetes mellitus was the predominant risk factor in posterior subcapsular cataract. The most frequent cause of presenile cataracts in our research, as in most other studies, was idiopathic. The most common morphological type of cataract was posterior subcapsular cataract in nearly half of the patients. In addition, case-control trials are required in this category to determine the cause of early cataract onset and to evaluate modifiable risk factors.

\section{ACKNOWLEDGEMENT}

We would like to thank all the participating clinicians for their cooperation in this study.

Funding: No funding sources

Conflict of interest: None declared

Ethical approval: Institutional ethical committee approval was obtained for this study 


\section{REFERENCES}

1. Lim JC, Caballero Arredondo M, Braakhuis AJ, Donaldson PJ. Vitamin C and the Lens: New Insights into Delaying the Onset of Cataract. Nutrients. 2020 Oct;12(10):3142.

2. Panozzo G, Staurenghi G, Dalla Mura G, Giannarelli D, Alessio G, Alongi S, Appolloni R, Baldascino A, Boscia F, Caporossi A, Cereda M. Prevalence of diabetes and diabetic macular edema in patients undergoing senile cataract surgery in Italy: The DIabetes and CATaract study. European journal of ophthalmology. 2020 Mar;30(2):315-20.

3. Song P, Wang H, Theodoratou E, Chan KY, Rudan I. The national and subnational prevalence of cataract and cataract blindness in China: a systematic review and metaanalysis. Journal of global health. 2018 Jun;8(1).

4. Hugosson M, Ekström C. Prevalence and risk factors for age-related cataract in Sweden. Upsala Journal of Medical Sciences. 2020 Oct 1;125(4):311-5.

5. Singh S, Pardhan S, Kulothungan V, Swaminathan G, Ravichandran JS, Ganesan S, Sharma T, Raman R. The prevalence and risk factors for cataract in rural and urban India. Indian journal of ophthalmology. 2019 Apr;67(4):477.

6. Pokhrel AK, Smith KR, Khalakdina A, Deuja A, Bates MN. Case-control study of indoor cooking smoke exposure and cataract in Nepal and India. International Journal of Epidemiology. 2005 Jun 1;34(3):702-8.

7. Mukhtar S, Ambati BK. The value of nutritional supplements in treating agerelated macular degeneration: a review of the literature. International ophthalmology. 2019 Jul 16:1-9.

8. Wu J, Zhou J, Ping X, Xu X, Cui Y, Yang $H$, Yin $Q$, Shentu $X$. Scanning and transmission electron microscopy study of anterior lens epithelium in presenile cataract. International Ophthalmology. 2020 Mar 6:1-8.

9. Hsieh YC, Chang CH, Tsai YY, Lin CL, Ng TY, Chiang CC. Increased risk of tinnitus in patients with early-onset cataracts: a nationwide population-based case-control study. BMC ophthalmology. 2020 Dec;20(1):1-7.

10. Adekoya BJ, Ekumankama CB. Clinical characteristics and outcome of surgery for pre-senile cataract among patients attending lagos state university teaching hospital. Annals of Clinical Sciences Volume. 2020 Jan;5(1).

11. Bomotti S, Lau B, Klein BE, Lee KE, Klein R, Duggal P, Klein AP. Refraction and Change in Refraction Over a 20-Year Period in the Beaver Dam Eye Study. Investigative ophthalmology \& visual science. 2018 Sep 4;59(11):4518-24.

12. Tan AG, Mitchell P, Rochtchina E, Flood VM, Cumming RG, Wang JJ. Serum homocysteine, vitamin B12, and folate, and the prevalence and incidence of posterior subcapsular cataract. Investigative ophthalmology \& visual science. 2015 Jan 1;56(1):216-20.

13. Lee H, Jin Y, Roh M, Tsacogianis TN, Park S, Choi NK, Kim SC. Risk of Cataract Surgery and Age-Related Macular Degeneration After Initiation of Denosumab vs Zoledronic Acid for Osteoporosis: A Multi-Database Cohort Study. Drugs \& Aging. 2020 Feb 6:1-0.

14. Öktem Ç, Aslan F. Vitamin D Levels in Young Adult Cataract Patients: A CaseControl Study. Ophthalmic research. 2020 Jun 23.

15. Tan AG, Flood VM, Kifley A, Russell J, Cumming RG, Mitchell P, Wang JJ. Wholegrain and legume consumption and the 5-year incidence of age-related cataract in the Blue Mountains Eye Study. British Journal of Nutrition. 2020 Mar 19:1-0.

16. Bhargava P, Jain K, Maherda L. A study of risk factors and epidemiologic profile of posterior polar cataract/posterior subcapsular cataract in Northwest Rajasthan. International Journal of Medical Science and Public Health. 2020;9(5).

17. Thorne JE, Woreta FA, Dunn JP, Jabs DA. Risk of cataract development among children with juvenile idiopathic arthritisrelated uveitis treated with topical corticosteroids. Ophthalmology. 2020 Apr 1;127(4):S21-6.

18. Vashist P, Tandon R, Murthy GV, Barua CK, Deka D, Singh S, Gupta V, Gupta N, Wadhwani M, Singh R, Vishwanath K. Association of cataract and sun exposure in geographically diverse populations of India: The CASE study. First Report of the ICMREYE SEE Study Group. PloS one. 2020 Jan 23;15(1):e0227868.

19. Fekri Y, Ojaghi H, Sharghi A, Ranjbar A, Zahirian Moghadam T. A study of 
Dhanya V S et.al. Risk factors and types of presenile cataract in patients attending a Tertiary Care Hospital in Kerala- a retrospective study.

Morphology of Cataract in Surgery Candidates in Ardabil: Iran. Journal of Ardabil University of Medical Sciences. 2020;20(1):127-36.

20. Malhotra C, Dhingra D, Nawani N, Chakma $\mathrm{P}$, Jain AK. Phacoemulsification in posterior polar cataract: Experience from a tertiary eye care Centre in North India. Indian Journal of Ophthalmology. 2020 Apr; 68(4):589.

21. Garrigan H, Ifantides C, Prashanthi GS, Das AV. Biogeographical and Altitudinal Distribution of Cataract: A Nine-Year
Experience Using Electronic Medical Record-Driven Big Data Analytics in India. Ophthalmic Epidemiology. 2020 Nov 21:18.

How to cite this article: Dhanya V S, Abraham M, Deepa MG. Risk factors and types of presenile cataract in patients attending a tertiary care hospital in Kerala- a retrospective study. International Journal of Research and Review. 2021; 8(2): 26-33. 